\title{
ESTUDIAR EL CINE ${ }^{1}$
}

\section{Manuel GONZÁLEZ DE ÁVILA}

Universidad de Salamanca

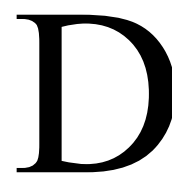
esde hace ya décadas, el cine es uno de los sectores más vivos de los estudios de humanidades y de comunicación y cultura. Nada tiene ello de extraño, pues el fenómeno cinematográfico reúne todas las características necesarias para convertirse en el interlocutor privilegiado de nuestras preocupaciones contemporáneas, un interlocutor al que el sujeto (hipermoderno o transmoderno, ¿qué más da?) no se cansa de dirigir sus angustiadas preguntas rituales acerca de sí mismo y del mundo en el que vive. Y si del cine, a pesar de que muestre ciertos signos de desgaste, aún esperamos respuestas, eso quizá se deba a que seguimos viendo en él un lugar de encuentro perfecto para nuestras teorías y para nuestras prácticas culturales, para el arte y para la industria, para el espíritu y para la economía.

Los principales recelos que la institución cinematográfica hizo surgir en la conciencia de los intelectuales desde su conversión en el arte de masas del siglo XX parecen haberse disipado definitivamente. Hoy nadie duda de que el cine, por ejemplo, sea un lenguaje con todo derecho; no una lengua punto por punto comparable a la verbal, dotada de un vocabulario estable y de una gramática estricta, pero sí un lenguaje plástico, fluido, de reglas flexibles, que se las ingenia para absorber los códigos de la comunicación cotidiana y para mimetizar un buen número de otros heredados de lenguajes artísticos precedentes y bien consolidados, como los de la pintura y la literatura. Tampoco son muchos los que niegan que el mejor cine es lo más cerca que los hombres han llegado a estar de la famosa «obra de arte total», con la que sueñan los creadores occidentales al menos desde el Romanticismo, y que no es otra cosa que la utopía retroactiva de un regreso hacia la fusión inextricable de imagen, palabra, música y movimiento que probablemente se dio en los rituales prehistóricos celebrados en las cavernas; una fusión numinosa cuyas virtudes epifánicas el cine retiene o contiene todavía. Esa es, acaso, la causa profunda de que en la actualidad seamos aún tan sensibles a la función mitogenética de la institución cinematográfica, a su inagotable capacidad para fabricar personajes y relatos que se adhieren a nuestro imaginario colectivo y prolongan en él las resonancias de otros personajes y de otros relatos fundacionales y fundamentales. De ahí también la susodicha

\footnotetext{
${ }^{1}$ Este texto se inscribe dentro del proyecto Lenguaje, ciencia y epistemología (FFI2014-53165-P), Programa Estatal de Investigación Científica y Técnica de Excelencia, Subprograma Estatal de Generación de Conocimiento.
} 
transformación del cine no solo en el arte dominante, sino igualmente en el patrón de medida para toda práctica simbólica durante el siglo XX; o, como dicen los semiólogos con mayor propiedad, en el automodelo cultural del que la pasada centuria se dotó a sí misma. La literatura, la filosofía, la plástica e incluso la música posterior a la segunda guerra mundial se han visto obligadas a confrontarse con el poder del cine para formar y conformar la visión del mundo de su espectador, y para someterlo a una dulce catarsis generalizada, a una revocación de las pasiones que pasa, primero y ambiguamente, por su convocación inmediata.

Aun cuando haya ganado definitivamente sus credenciales de nobleza cultural, la institución cinematográfica del siglo XXI está sometida a una fuerte tensión centrífuga. En estos tiempos de mutaciones e hibridaciones, de inseguridad de los valores estéticos y de ampliación de los cánones artísticos, el cine, ese lugar de encuentro entre el espíritu y la economía, sirve en tanto gigantesco melting-pot planetario donde el denso magma de nuestra cultura verbal y visual bulle y salpica en todas direcciones. Así, el dispositivo cinematográfico intercambia, como dijimos, estrategias comunicativas con otros vehículos como la literatura, el teatro, el cómic, la televisión o los videojuegos, en lo que se ha denominado una transmedialidad sistemática; cultiva alegremente con ellos un mismo acervo de relatos interconectados en una transficcionalidad ampliada; y con ellos comparte técnicas de enunciación y tácticas de estilo, practicando una transescritura metódica. El resultado de la convergencia de tantas operaciones de fusión y confusión tecnosimbólica es que hoy una buena historia se lee, se escucha, se contempla, se olfatea, se degusta y se palpa a través de la totalidad de nuestros canales sensoriales y sobre múltiples soportes diferentes: hemos entrado en el reino de una transestesia generalizada donde los límites entre el cuerpo y la mente, entre lo vivido y lo concebido, son o parecen ser convencionales, y el cine tiene aún mucho que aportar a ese universo de una cultura total, y quizá totalitaria.

Porque, claro está, detrás de la cuestión estética late la cuestión epistemológica; y, detrás de esta, la cuestión política. Seguimos, en suma, anclados a la pregunta que Platón se hiciera en La República a propósito del orden social justo y de la participación en él de los distintos lenguajes, de las diversas formas simbólicas. El cine, lenguaje sincrético, forma simbólica consumada, matriz mitológica y metamodelo cultural «trans», lo tiene todo para alimentar las guerras contemporáneas del saber y del poder: el debate sobre el enigmático estatuto ontológico de la imagen en nuestras sociedades, a medio camino entre el ser y el parecer, entre la realidad y la ficción, y su todavía más inasible régimen de veridicción, que mezcla verdades y mentiras, falsedades y secretos (así los docudramas, los pseudocumentales, las autoficciones); la polémica del feminismo y las reivindicaciones de las minorías sexuales, étnicas, religiosas (así el cine de la diferencia y del diferencialismo); las discusiones sobre la multiculturalidad deseable y la interculturalidad inalcanzable -o al revés-, y sobre los integrismos que aquellas pretenden combatir o compensar (así en particular las filmografías del mundo ahora púdicamente llamado «periférico»); la querella sobre la existencia o inexistencia de la lucha de clases y de grupos en el orden socioeconómico mundial (así el cine calificado de «político» o de «comprometido», ese que tan bien describe el vigente y hobbesiano bellum ómnium contra omnes); la 
denuncia de la dominación y explotación de la naturaleza hasta su más que probable destrucción antrópica (así el «ecocine», al que se vincula la extensión de la «ecocrítica» en los estudios de humanidades); y un largo etcétera.

Tal enumeración de los puntos de litigio que sociedades en permanente conflicto consigo mismas encuentran forma de abordar en sus filmes podría proseguirse casi ad infinitum. Pero no es necesario para atreverse a sacar ya al menos una conclusión, útil antes de afrontar cualquier estudio sobre cine: la de la cuádruple relevancia que la institución cinematográfica reviste para nosotros. Relevancia semiótica, en primer lugar, porque el dúctil lenguaje del cine prueba que la cultura es una tupida red de signos, de textos y de discursos interrelacionados, donde se combinan modos sensoriales y cognitivos plurales. Relevancia mediológica con implicaciones tecnocientíficas, en segundo lugar, dado que el cine no es solo producto de los medios y de la tecnología, sino que también contribuye a su desarrollo. Relevancia psicológica o psicoanalítica, en tercer lugar, ya que el dispositivo cinematográfico ilumina la naturaleza a la vez verbal y visual del imaginario, alimentado por la incesante semiogénesis social. Y relevancia sociológica, en cuarto y último lugar, desde el momento en que ese imaginario verbovisual compuesto de signos de cultura es un espacio de proyección -nunca mejor dicho- y de elaboración de los antagonismos sociales, y no únicamente de nuestras escisiones pulsionales y pasionales. Con ello bastaría para seguir prestando al cine la atención que merece. 